\title{
INOVAÇÃO EM SISTEMAS DE PRODUÇÃO DE ARROZ ORGÂNICO NO RIO GRANDE DO SUL
} INNOVATION IN PRODUCTION ORGANIC
RICE SYSTEMS IN RIO GRANDE DO SUL

\author{
Recebido 05/10/2012 \\ Aceito $02 / 02 / 2013$ \\ Vanessa Monks da Silveira ${ }^{1}$ \\ Graziela Mota Antunes ${ }^{2}$ \\ Marcelo Fernandes Pacheco Dias ${ }^{3}$
}

\section{RESUMO}

O Rio Grande do Sul é o maior produtor brasileiro de arroz. No estado, o arroz é convencionalmente produzido em grandes áreas, com o uso intensivo de máquinas e de insumos, o que tem sido associado a impactos ambientais. A inovação pode contribuir para a mudança dessa realidade. Algumas iniciativas estão sendo desenvolvidas nos últimos anos, buscando adaptar o sistema convencional à tendência mundial de consumo preocupado com o meio ambiente. Um exemplo é a produção de arroz orgânico. Nesse sentido, estabeleceu-se como objetivo identificar os grupos de produção orgânica no estado do Rio Grande do Sul e as inovações associadas a estes grupos. O delineamento da pesquisa caracterizou-se como qualitativo. $\mathrm{O}$ atual estágio da pesquisa possibilitou identificar o grupo de produtores associados ao Núcleo de Educação Ambiental e o Grupo Gestor de Arroz Agroecológico, coordenado à Cooperativa Central dos Assentamentos do Rio Grande do Sul. Já foram identificados outros produtores ou grupos. Quanto às inovações, os resultados do grupo dos produtores associados ao Núcleo de Educação e Monitoramento Ambiental estão em análise. Ainda assim, foi possível constatar que novas alternativas, mais sustentáveis, estão sendo adotadas pelos produtores e que esse tipo de cultivo vem crescendo nas últimas safras.

Palavras-chave: Inovação; Arroz; Orgânico; Agroecológico

${ }^{1}$ Engenheira Agrônoma, mestre em Pastagens pela Universidade Federal de Pelotas. Consultora na área de Gestão Ambiental da Universidade Católica de Pelotas no NESIC- Núcleo de Economia Solidária e Incubação de Cooperativas e colaboradora na Universidade Federal de Pelotas no GPEIA - Grupo de Pesquisa em Inovação e Sustentabilidade no Agronegócio. Pelotas, Rio Grande do Sul, Brasil. E-mail: nessamonks@hotmail.com

${ }^{2}$ Bacharel em Administração (2012), pela Universidade Federal de Pelotas. Colaboradora na Universidade Federal de Pelotas no GPEIA - Grupo de Pesquisa em Inovação e Sustentabilidade no Agronegócio. Pelotas, Rio Grande do Sul, Brasil. E-mail: grazimota@hotmail.com

${ }^{3}$ Graduado em Agronomia mestre em Administração e doutor em Agronegócios pela Universidade Federal do Rio Grande do Sul. Professor na Faculdade de Administração e Turismo da Universidade Federal de Pelotas e coordenador do GPEIA - Grupo de Pesquisa em Inovação e Sustentabilidade no Agronegócio. Pelotas, Rio Grande do Sul, Brasil. E-mail: mfpdias@hotmail.com 


\section{ABSTRACT}

The Rio Grande do Sul is the largest producer of rice. In the state, rice is conventionally produced in large areas with intensive use of machinery and inputs, which has been associated with environmental impacts. Innovation can help to change this reality. Some initiatives are being developed in recent years trying to adapt the conventional system the global trend of consumption concerned about the environment. An example is the production of organic rice. In this sense, has established itself as objective to identify the groups of organic production in the state of Rio Grande do Sul and the innovations associated with these groups. The research was characterized as qualitative. The current stage of research enabled us to identify the group of producers associated with the Center for Environmental Education and Rice Agroecological Management Group, coordinated the Cooperative Central Settlements of Rio Grande do Sul. Have been identified other producers or groups. As for innovations, the results of the group of producers associated with the Center for Environmental Education and Monitoring are under review. Still it was found that new more sustainable alternatives are being adopted by producers and that this type of cultivation has increased in recent seasons.

Keywords: Innovation; Rice, organic; Agroecological

\section{INTRODUÇÃO}

A agricultura é de fundamental importância para o desenvolvimento econômico do Brasil, com uma das maiores áreas agricultáveis do planeta. O Brasil tem potencial para crescer ainda mais nesse setor, sem necessidade de expandir a fronteira agrícola. Em um contexto atual, no qual muitos países encontram dificuldade em produzir alimentos para atender sua demanda interna, 0 Brasil ocupa um papel de ser um dos maiores fornecedores de alimentos do mundo. Entre culturas mais cultivadas no Brasil, destaca-se o agronegócio do arroz. O país é o nono produtor mundial de arroz e um dos maiores exportadores e importadores de arroz do mundo (ANUÁRIO, 2011).

Considerando-se os problemas econômicos e ambientais enfrentados pela cadeia tradicional do arroz no Rio Grande do Sul, a necessidade de desenvolver inovações ambientais, a crescente adoção do cultivo do arroz orgânico, e o fato de o desenvolvimento de inovações ser algo complexo, ainda mais em nas pequenas propriedades, estabelece-se como o objetivo deste artigo identificar os grupos de produção orgânica no estado do Rio Grande do Sul e as inovações associadas a estes grupos.

Para isso, buscou-se organizar este artigo da seguinte forma: na seção 2, buscou-se revisar a literatura sobre inovação e produção orgânica; na seção 3, é apresentada a metodologia; na seção 4, são apresentados os resultados, com ênfase para ainda na identificação dos grupos de produção orgânica.

\section{REVISÃO DE LITERATURA}

\subsection{Cultivo do Arroz no Rio Grande do Sul}

A produção brasileira de arroz está cada vez mais concentrada nas lavouras irrigadas do Sul do país, daí a importância desse grão para a economia do estado do Rio Grande do Sul. O cultivo do arroz foi introduzido no país no século XVI e desenvolveu-se no Rio Grande do Sul, a partir de 1930, com um crescente aporte de tecnologia e produtividade. Atualmente, é a segunda cultura mais importante do estado, ficando atrás somente da soja (IRGA, 2012).

$\mathrm{O}$ arroz, no estado do Rio Grande do Sul, é cultivado em grandes áreas altamente tecnificadas e sistematizadas, com uso intensivo de máquinas, insumos e recursos naturais, com vistas à busca da maior produtividade possível. Esse foco na produtividade faz com que aumen- 
te, consideravelmente, a probabilidade de contaminação das águas, além de causar a perturbação dos processos ecológicos e prejudicar os micro-organismos benéficos; contudo pode, ainda, causar sérios problemas de saúde tanto para os produtores quanto para os consumidores (FAO, 2002). Em parte, os problemas causados pela excessiva produtividade podem ser evidenciados no programa desenvolvido pela Agência Nacional de Vigilância Sanitária (ANVISA), denominado de Programa de Análise de Resíduos de Agrotóxico em Alimentos - PARA. Esse programa auxilia o Governo a combater os níveis de resíduos de agrotóxicos presentes nos alimentos in natura. No arroz, a vigilância encontrou $26,5 \%$ de ingredientes ativos não autorizados. Essa situação pode ser considerada grave, pois o consumo de alimentos com agrotóxicos tem sido relacionado a várias doenças, como alguns tipos de câncer, intoxicação, depressão, má formação congênita ou, ainda, transtornos da imunidade (GLOBO, 2011).

Além de gerar grandes danos ao meio ambiente, outro fator que tem preocupado os atores do agronegócio do arroz são os baixos preços recebidos, principalmente nas safras em que há excedente de produção. Numa análise de série temporal do preço do arroz entre 1975 e 2010, identificou-se uma queda de $4,0 \%$ ao ano e projeção futura de baixa (SOSBAI, 2010).

Considerando essa dualidade, vários autores defendem a mudança de foco no desenvolvimento das inovações, reivindicando que sejam incorporados elementos de sustentabilidade (TILMAN et al., 2001; LOVINS, A.; LOVINS, L.; HAWKEN, 2007; FAO, 2008, CARACA; LUNDVALL; MENDONCA, 2009). Nesse contexto, um dos principais desafios a serem superados pelas organizações é a necessidade de incorporar, em suas estratégias, a perspectiva de práticas inovadoras com vistas à sustentabilidade. Para isso, as organizações devem implementar estratégias que integrem inovação e desenvolvimento sustentável, de modo a atender simultaneamente às pressões ambientais e econômicas e de modo não irreconciliável com o crescimento econômico (HART; MILSTEIN, 2003). Por outro lado, entende-se o desenvolvimento de inovações como algo complexo, ainda mais nas pequenas propriedades, onde não há recursos para investir em pesquisa e desenvolvimento.

Nesse contexto, surge o sistema de produção de arroz orgânico como possibilidade de redução do impacto ambiental e de transformação do produto em diferenciado no mercado, com agregação de valor e melhor remuneração do produtor. Produtos orgânicos são todos aqueles, quer sejam de origem vegetal, quer sejam de animal, produzidos livre de agrotóxicos ou qualquer outro tipo de produtos químicos, pois estes são substituídos por práticas culturais que buscam estabelecer o equilíbrio ecológico do sistema agrícola (BRASIL, 2007). A busca por alimentos saudáveis é uma tendência mundial e também é observada no Brasil. Nos últimos anos, o que se observa é que vem crescendo o consumo de alimentos orgânicos, assim como a sua produção, inclusive do arroz. Muitas vezes a demanda por este tipo de produto é bem maior que a oferta, o que cria um mercado promissor para os produtores.

\subsection{Inovação}

A inovação ambiental ou eco-innovation é um conceito recente no contexto de inovação, e se começou a discutir o assunto a partir da década de 1990 (KEMP \& PEARSON, 2007). O que distingue inovação ambiental do conceito de inovação tradicional é o fato que a primeira abrange os ganhos ambientais gerados quando comparados com outras tecnologias (KEMP \& ARUNDEL, 1998). A OCDE (2003) define inovação como a transformação de uma ideia em um produto novo ou melhorado que se introduz no mercado; ou em novos sistemas de produção; ou em difusão, comercialização e utilização. No conceito, é possível perceber que a inovação envolve um processo e que esta poderá resultar em produtos ou serviços finais. 
No processo de inovação, a informação é de fundamental importância. Na busca de informações, elas podem ser obtidas internamente (fontes endógenas) ou externamente (fontes exógenas) à firma. Internamente, as fontes são o departamento de P\&D e as demais áreas da empresa. Externamente, as fontes são as instituições públicas de pesquisa; o fluxo de informações interfirma e interindústria, que pode ocorrer no âmbito do país, como também entre outros mercados, competidores, clientes ou consumidores, firmas de consultoria, fornecedores de equipamentos e matérias-primas (OECD, 2003; PIGATTO, SCHIAVI E SOUZA FILHO, 2005).

$\mathrm{Na}$ busca de informações externas, as empresas podem desenvolver arranjos com outras organizações. Tradicionalmente, os relacionamentos com fornecedores, clientes e concorrentes são vistos exclusivamente como competitivos. Entretanto, o conceito de "coopetição" - cooperar e competir de forma simultânea para obter maior competitividade (NALEBUFF e BRANDENBURGER, 1996) - propõe superar esse paradigma. Estudos na área de inovação indicam que o potencial de inovação é correlacionado com o número de relacionamentos, tanto competitivos como colaborativos, existentes entre as organizações (MIOTTI, 2003). Em organizações nas quais a inovação é uma fonte de vantagem competitiva, a estratégia de "coopetição" tem papel importante, de tal forma que novos produtos, processos de produção, formas organizacionais e novos mercados são eficazmente competitivos. Isso ocorre devido ao aumento do acesso a novos conhecimentos, à aprendizagem organizacional, às novas tecnologias, aos produtos complementares, permitindo ampliar a capacidade tecnológica e o processo de inovação (JORDE e TEECE, 1989). Nos relacionamentos essencialmente cooperativos com universidades e institutos de pesquisas, o objetivo é o acesso aos especialistas e equipamentos a fim de complementar o setor de pesquisa e desenvolvimento (TIDD; BEASSANT; PAVITT , 1997; THETER, 2002).

Mesmo que a informação esteja disponível para todos os agentes do mercado, o conhecimento pode não estar, devido ao esforço necessário para compreendê-lo e explorá-lo (ARUNDEL et al., 1998). Esse fenômeno está relacionado à capacidade absortiva. Cohen, Levinthal e Daniel (1990) definiram capacidade absortiva como o conhecimento prévio que confere uma habilidade ou capacidade para reconhecer o valor de uma nova informação, assimilá-la e aplicá-la com fins comerciais. A capacidade absortiva pode ser de dois tipos: capacidade absortiva organizacional e capacidade absortiva individual.

Como resultado, as inovações podem ser de quatro tipos. Elas podem ser radicais ou incrementais (ABERNATHY e UTTERBACK, 1978; FREEMANN, 1988). Segundo Freemann (1988), a inovação radical pode ser entendida como um novo processo, produto ou uma forma de organização diferente; enquanto as inovações incrementais referem-se à introdução de melhorias, sem alteração na estrutura industrial. Também podem ser em processo ou produto. Inovações em produto significam novos produtos ou serviços para satisfazer um usuário externo ou uma necessidade de mercado. E inovações em processos são novos elementos introduzidos na organização das operações para oferecer um produto ou serviço (KNIGHT, 1967).

\subsection{Agricultura Orgânica}

Agricultura Orgânica não é uma ideia recente, pois se considera como orgânica praticamente toda a agricultura realizada com baixa tecnificação, ou por quem não tem acesso a insumos (BRASIL, 2007). Porém, a ideia central desta atividade é ser livre de agrotóxicos. Esse é o grande propulsor do movimento. Agricultura Orgânica inseriu a ideia de evitar uso de venenos e outros valores, como o equilíbrio ambiental, o respeito aos trabalhadores, o ato de evitar adubos de alta solubilidade, e o aumento da qualidade do produto (BRASIL, 2011). 
Inicialmente, o termo agricultura orgânica foi usado para designar uma forma alternativa de agricultura, que objetivava contrapor-se à agricultura tradicional. Dessa forma, a agricultura orgânica reúne todos os modelos não convencionais de agricultura, tais como: biodinâmica, natural, biológica, permacultura ou agroecológica, para se contrapor ao modelo convencional (SOUZA FILHO, 2001). Atualmente, o artigo 1ㅇ da Lei de no 10.831, de 23 de dezembro de 2003, especifica a abrangência da agricultura orgânica através da definição de sistema orgânico.

Considera-se sistema orgânico de produção agropecuária, todo aquele em que se adotam técnicas específicas, mediante a otimização do uso dos recursos naturais e socioeconômicos disponíveis e o respeito à integridade cultural das comunidades rurais, tendo por objetivo à sustentabilidade econômica e ecológica, a maximização dos benefícios sociais, a minimização da dependência de energia não renovável, empregando sempre que possíveis métodos culturais, biológicos e mecânicos, em contraposição ao uso de materiais sintéticos, a eliminação do uso de organismos geneticamente modificados e radiações ionizantes, em qualquer fase do processo de produção, processamento, armazenamento, distribuição e comercialização. E a proteção do meio ambiente (BRASIL, 2007).

A mesma lei define como produto orgânico "aquele obtido em sistema orgânico de produção agropecuária ou oriundo de processo extrativista sustentável e não prejudicial ao ecossistema local". Dessa forma, para que um produto seja considerado orgânico, este deve ter, em toda a sua cadeia produtiva, a preocupação com as exigências feitas na Lei 10.831, de 23 de dezembro de 2003, não bastando ter essa preocupação apenas na produção da matéria-prima, mas durante todo o processo agroindustrial (BRASIL, 2011).

A certificação é uma atividade importante que visa a contribuir para a confiabilidade da produção orgânica. Certificação é a definição de atributos de produtos, processos ou serviços e a garantia de que eles se enquadrem em normas predefinidas, é uma ferramenta que oferece procedimentos e padrões básicos para as empresas gerenciarem o nível de qualidade de seus produtos e garantirem um conjunto de atributos. Do lado da demanda, busca informar ao consumidor que aquele determinado produto tem os atributos por ele procurados (NASSAR, 1998).

Nos produtos orgânicos, a certificação é a forma de controle de sua procedência e de sua diferenciação na forma produtiva, em relação à convencional, ressaltando os atributos de qualidades dos produtos orgânicos, assim como a ausência de resíduos tóxicos e a presença de extremidades positivas ao meio ambiente, em seu processo produtivo, dificilmente observáveis na hora da compra, e que podem possibilitar ações oportunistas por parte dos vendedores (SOUZA, 2000). A certificação, nesse caso, constitui um elemento de redução da forte assimetria de informações existentes entre vendedores e consumidores, dificultando a adoção de práticas oportunistas, motivadas pela possibilidade do preço-prêmio, normalmente atribuído aos orgânicos (SOUZA, 2000)

Os movimentos de certificação para diferenciar produtos e produtores agrícolas são originários da Europa. O primeiro e o mais importante organismo mundial do movimento de certificação orgânica é a International Federation of Organic Agriculture Movements (IFOAM), que elaborou as normas básicas. A partir dessas normas, cada entidade certificadora elabora normas com o rigor e o nível de detalhamento condizentes com as características ambientais e socioeconômicas de cada região ou país (PASCHOL, 1994).

No Brasil, os pioneiros na certificação de produtos orgânicos são o Instituto Biodinâmico de Desenvolvimento Rural (IBD), sediado em Botucatu (SP), avalizado pelo IFOAM, e cujo selo é aceito em mercados internacionais; e a Associação de Agricultura Orgânica (AAO), cujo selo é aceito nacionalmente. Outras certificadoras nacionais que atuam regionalmente são: a Associação de Agricultura Nacional de Campinas e Região (ANC); a Associação dos Produtores 
de Agricultura Natural (APAN); a Fundação Mokite Okada (MOA); a COOLMÉIA, no Rio Grande do Sul; e a Associação de Agricultores Biológicos do Rio de Janeiro (ABIO). Atualmente, existem aproximadamente 25 selos de certificadoras no país (Brasil, 2011).

\section{METODOLOGIA}

O delineamento da pesquisa caracterizou-se como pesquisa qualitativa, pois buscou identificar e descrever os grupos ou produtores de arroz orgânico e as inovações associadas a estes grupos. A coleta de dados se deu através de documentos e entrevistas não estruturadas. Inicialmente, buscou-se identificar e descrever os grupos ou produtores orgânicos através de documentos identificados na internet. Os documentos foram identificados através de palavras-chave. Foram utilizadas as palavras chaves: "arroz" e "Rio Grande do Sul", combinadas com as palavras "orgânico", "agroecológico", "biodinâmico", "natural" e "ecológico". A proposta da pesquisa em documentos teve o intuito de uma familiarização prévia do pesquisador antes das entrevistas e do maior detalhamento após elas.

Uma vez realizada a localização dos grupos e/ou produtores orgânicos e uma leitura previa dos documentos, buscou-se realizar as entrevistas abertas com o propósito de compreender como foi a evolução, ao longo do tempo, desses grupos de produtores orgânicos. A questão central que orientou esta etapa de pesquisa foi a seguinte: Como foi a evolução do grupo de produtores de arroz orgânico (fatores que contribuíram para início, produção, área, número de produtores, do início até hoje)? Uma segunda questão aberta que foi realizada buscou identificar as inovações. Foi realizada a seguinte questão de pesquisa: "Você pode fazer uma descrição da trajetória/evolução do sistema de produção de arroz orgânico (do início até hoje)? As técnicas de produção foram sendo aprimoradas/adotadas ao longo do tempo?". Nesta fase de entrevista, novos documentos foram obtidos por indicação dos entrevistados, o que contribuiu também para o detalhamento das organizações e inovações.

Para facilitar a análise, foi realizada a transcrição de todas as entrevistas. Uma vez as entrevistas transcritas, os documentos também foram organizados com o propósito de facilitar a análise dos resultados. A análise realizada foi de conteúdo (BARDIN, 1977). A análise de conteúdo é definida como um conjunto de procedimentos que englobam as fases de classificar os conceitos, codificá-los e categorizá-los. Uma característica dessa análise está na importância do indivíduo aplicador da pesquisa ter vasto conhecimento sobre a teoria e dominar os conceitos que estão servindo de base para o conteúdo das mensagens. A metodologia da análise de conteúdo é dividida, principalmente, em três partes: a pré-análise; a exploração do material; e o tratamento dos resultados, a inferência e a interpretação (BARDIN, 1977).

A fase de pré-análise tem como objetivo a organização dos dados, após uma rápida leitura destes. Nessa fase, tornam-se operacionais e sistemáticas as ideias iniciais, através de um plano de análise. A fase da descrição analítica ou exploração do material caracteriza-se por um estudo profundo do material coletado segundo as hipóteses e, ainda, baseando-se em referências teóricas. Nessa fase, há também a codificação e categorização dos dados. E, no estágio da interpretação inferencial dos resultados, é necessária a análise das evidências coletadas, com fundamentos teóricos para se alcançar ligações pertinentes (BARDIN, 1977).

Para fazer a descrição dos grupos ou produtores orgânicos, não foi utilizada nenhuma categoria previa. Adotou-se uma lógica indutiva, no sentido de identificar categorias que melhor pudessem descrever o sistema de produção de arroz orgânico em análise. Para identificar as inovações, estabeleceram-se como categorias os quatro tipos de inovação: radicais, incrementais, de produto e de processo. 


\section{RESULTADOS E CONCLUSÕES}

Dois grupos de produtores orgânicos foram identificados e descritos no atual estágio de pesquisa: produtores orgânicos do movimento sem terra associados ao Grupo Gestor e produtores orgânicos associados ao Núcleo de Educação e Monitoramento Ambiental - NEMA. Esses dois grupos são descritos a seguir.

\subsection{Produtores orgânicos do movimento sem terra associados ao grupo Gestor}

O Grupo Gestor do Arroz Ecológico se originou dos assentamentos da região metropolitana de Porto Alegre, onde a principal fonte de renda sempre foi o cultivo de arroz irrigado. A opção ao cultivo do arroz foi devido ao tipo de solo, topografia, clima e condições hidrográficas que favoreciam a essa cultura. Estes assentamentos iniciaram com a produção de arroz tradicional, baseado no uso de fertilizantes químicos, agrotóxicos e mecanização pesada. Porém, logo se começou a perceber os efeitos negativos para a economia, saúde e o ambiente dos assentamentos, como o endividamento crescente pela falta de estrutura e alto custo de produção, as doenças associadas ao uso de agrotóxicos e a consequente degradação ambiental (VIGNOLO, 2010).

O cultivo agroecológico se iniciou em 1998/1999, apenas com hortaliças em pequenas unidades nos mercados locais, entrega direta ao consumidor e em feiras. Em 1999, com a crise do setor orizicola, devido ao preço baixo de comercialização, que não cobriam os custos de produção, constitui-se uma equipe que representava os grupos e assentamentos que tinham potencial para produção e que se propunham a produzir o arroz ecológico. Daí surgiu o Grupo Gestor do Arroz Ecológico (Grupo Gestor Arroz Ecológico, 2012).

A produção de arroz agroecológico começou a ser desenvolvida nos assentamentos da grande Porto Alegre, nos municípios de Nova Santa Rita, Tapes e Viamão (COCEARGS, 2012). Esse grupo contou com apoio da Cooperativa Central dos Assentamentos do Rio Grande do Sul - COCEARGS e Cooperativa de Prestação de Serviços Técnicos - COPTEC, que buscou apoio institucional nos órgãos de ensino, pesquisa e em experiências práticas de produção de arroz orgânico no Estado (Grupo Gestor Arroz Ecológico, 2012).

A experiência iniciou-se em áreas pequenas (de 3 a 4 hectares), no ano de 1999, basicamente no Assentamento da Capela, no município de Capela - RS, com a Cooperativa de Produção Agropecuária de Nova Santa Rita Ltda. - COOPAN; e no Assentamento Lagoa do Junco, no município de Tapes - RS, com a Cooperativa de Produção dos Assentados de Tapes - COOPAT (MENEGON et al., 2009).

Uma iniciativa que começou com apenas três municípios passou a ser disseminada por outros municípios, aumentando sua abrangência a cada safra. Dez anos após seu início (TABELA 1), na safra 2009/10, já se dobrava o número de municípios, chegando a abranger seis municípios (COCEARGS, 2012).

Tabela 1 - Assentamentos pertencentes ao Grupo Gesto do Arroz Ecológico/COCEARGS safara 2009/2010

\begin{tabular}{c|c|c}
\hline Assentamento & Município & Node unidades certificadas \\
\hline 19 de Setembro & Guaíba & 5 \\
IRGA & Eldorado do Sul & 7 \\
30 de Maio & Charqueadas & 14 \\
Lagoa do Junco & Tapes & 1 \\
Filhos de Sepé & Viamão & 81 \\
Capela & Nova Santa Rita & 14 \\
Santa Rita de Cássia & Nova Santa Rita & 25 \\
\hline
\end{tabular}

Fonte: Cooperativa Central dos Assentamentos do Rio Grande do Sul Ltda. (COCEARGS) e Grupo Gestor Arroz Ecológico.

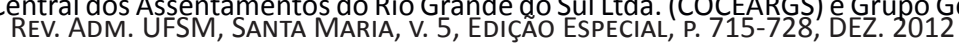


A área e a produção também cresceram. Na safra 2009/2010, chegou-se a uma área plantada de $2.104,6$ hectares, com uma produção de 177.767 sacas. (TABELA 2).

Tabela 2 - Dados da produção de arroz do Grupo Gestor Arroz Ecológico nas safras 2009/2010 e 2010/2011.

\begin{tabular}{l|c|c|c}
\hline \multicolumn{1}{c|}{ Dados Gerais } & Safra 2009/2010 & Safra 2010/2011 & Incremento (\%) \\
\hline Número de Assentamentos & 7 & 16 & 128,57 \\
\hline Número de Municípios & 6 & 11 & 83,33 \\
\hline Número de Famílias envolvidas & 211 & 428 & 102,84 \\
\hline Área total de arroz org. ou em transição (hectares) & $2.104,6$ & $3.880,57$ & 84,38 \\
\hline Produção total (sacas) & 177.767 & $344.627,88$ & 93,86 \\
\hline
\end{tabular}

Fonte: Cooperativa Central dos Assentamentos do Rio Grande do Sul Ltda. (COCEARGS) e Grupo Gestor Arroz Ecológico.

O sistema continua em fase de plena expansão, conseguindo um crescimento de quase $130 \%$ no número de assentamentos participantes, passando de sete para dezesseis na safra 2010/2011. Já na produção, esse aumento foi bem menor, chegando a aproximadamente 94\% (TABELA 2).

Atualmente, o desafio do Grupo Gestor do Arroz Ecológico é reduzir a área do sistema convencional, que ocupa uma área plantada de mais de cinquenta mil hectares e envolve um complexo agroindustrial que está dentro da cadeia do agronegócio. Para agregar esses produtores, o Grupo Gestor do Arroz Ecológico procura mostrar os impactos ambientais e culturais gerados pelo sistema convencional e, por segundo, mostrar a viabilidade econômica, ambiental e social na utilização da nova matriz tecnológica. Esse trabalho é realizado pelo Grupo Gestor através de seminários, palestras, encontros, dias de campo, conversas informais e outras formas, a fim de resgatar a cultura camponesa e a luta de classes (VIGNOLO, 2010).

\subsection{Grupo de produtores orgânicos associados ao NEMA}

Em meados de 1985, alguns alunos do curso de Oceanografia da FURG (Fundação Universidade Federal do Rio Grande), em parceria com a ABC (Autarquia do Balneário Cassino), fundaram o NEMA - Núcleo de Educação e Monitoramento Ambiental em Rio Grande - RS. A criação desse grupo se deu devido à preocupação de seus idealizadores com a situação ambiental do município. A sede do NEMA foi construída na beira da praia do Cassino e se mantém até hoje. 0 NEMA surgiu com a proposta de juntar o conhecimento científico de sua equipe com o conhecimento empírico da comunidade local. Mais do que convencer as pessoas da importância de se preservar as belezas do Planeta, o NEMA deu início a uma série de trabalhos de educação e monitoramento ambiental. Em seguida a sua criação, o NEMA, em 1987, passou a ter personalidade jurídica. Sendo, então, caracterizado como uma associação privada sem fins lucrativos, e de utilidade pública municipal. (NEMA, 2012).

Em 2002, o Governo Federal lançou um edital para a elaboração de planos de desenvolvimento sustentável no entorno de unidades de conservação, que são estações ecológicas, reservas biológicas e parques nacionais. São localidades onde as atividades são as mais restritas possíveis. Embora seja uma boa estratégia para conservar a biodiversidade, a preservação dessas unidades é uma ação que entra em conflito com as restrições que surgem às atividades socioeconômicas nas áreas de entorno a estas estações (REVICA, 2012).

A participação do NEMA neste edital, coordenado pelo MMA (Ministério do Meio Ambiente) e pelo CNPq (Conselho Nacional de Desenvolvimento Científico e Tecnológico), deu-se através da parceria do NEMA com a comunidade do Taim, em Rio Grande e em Santa Vitória do Palmar. Essas unidades juntas elaboraram um Plano de Desenvolvimento Sustentável. Na etapa 
de elaboração da sua proposta, o NEMA pesquisou as comunidades que citaram seus principais problemas e contribuíram com algumas sugestões de temas que poderiam ser trabalhados, como, por exemplo, a questão da pesca, a questão do desenvolvimento turístico no entorno da estação ecológica, a questão de um ordenamento territorial que permitisse essas comunidades se desenvolvessem (REVICA, 2012).

No momento em que o NEMA teve seu projeto aprovado, foram estabelecidas cinco ações prioritárias para a utilização sustentável de recursos da biodiversidade nas áreas de entorno de Unidades de Conservação de proteção integral localizadas em ecossistemas abertos. A implantação do Plano de Desenvolvimento Sustentável do Entorno da ESEC Taim se deu através das seguintes diretrizes: Implantação de um sistema de visitação orientada no entorno da ESEC (Estação Ecológica) Taim; Elaboração de um plano de diretrizes de ordenamento territorial para as comunidades da Capilha e Serraria; Viabilização da participação das comunidades na gestão da pesca artesanal da região; Estimulo à gestão participativa; Fomento das iniciativas ecológicas de produção agropecuária (PROBIO, 2004).

O Projeto Probio foi desenvolvido em duas fases. Na primeira fase, o NEMA apresentou planos de desenvolvimento sustentável em toda estação ecológica do Taim. Esse trabalho foi desenvolvido durante seis meses, quando o NEMA consultou: as lideranças dos dois municípios envolvidos no projeto; os agentes da estação ecológica do Taim; a comunidade do entorno e alguns consultores externos que fizeram a avaliação da proposta. As pesquisas desenvolvidas por esses consultores apontaram um dos problemas ambientais mais significativos presente na literatura, que é o cultivo de arroz na região, sendo considerado o principal conflito ambiental. A partir desse fato, foi incluída, na proposta, a 5a diretriz, que, conforme já citado, era a necessária existência de Fomento das iniciativas ecológicas de produção agropecuária. E, em resposta a esse desafio, o NEMA indicou a produção do arroz orgânico. Esta sugestão foi indicada mais no sentido de uma estratégia de conservação do que de uma estratégia comercial, já que o objetivo social do NEMA não é a questão comercial. (REVICA, 2012).

O plano elaborado pelo NEMA, após avaliado, foi implantado na segunda fase do Probio. Portanto, foi nesse momento que se começou a trabalhar com a questão da produção do arroz orgânico, de modo a atender a expectativa de se ter uma educação ambiental através da agricultura orgânica (REVICA, 2012).

Nas três primeiras safras, período de vigência do projeto, a contar a partir do ano de 2003, o NEMA teve o apoio financeiro para começar o trabalho. Esse incentivo foi destinado para todas as cinco áreas de ações traçadas anteriormente (REVICA, 2012). O fato de o projeto ter custeado toda a produção orgânica, além de não onerar os produtores envolvidos, foi o modo escolhido para tornar mais atrativa a entrada dos primeiros produtores nesse sistema de produção (GIGOTE, 2012).

No ano seguinte, o incentivo que o NEMA recebeu para a produção orgânica de arroz foi através do Fundo Nacional do Meio Ambiente. Essa etapa foi considerada de capacitação e treinamento, pois, embora não houvesse mais o financiamento da produção, foram realizados diversos cursos, palestras e demais eventos para discussão das práticas (REVICA, 2012).

Na safra de 2003/2004, o sistema orgânico do NEMA contava com apenas um secador para seus os 6 produtores envolvidos: 5 (cinco) da ATLA (Associação dos Trabalhadores da lavoura e do Arroz) e mais 1 (um) produtor individual, Frederico Costa. O principal objetivo motivador era plantar/produzir arroz orgânico, ou seja, sem agroquímicos. A área plantada foi de 7 (sete) hectares e meio. Obtiveram-se números satisfatórios, uma média de 100 sacos por hectare (REVICA, 2012).

Com o resultado da produtividade, surgiu a questão comercial. Em outras palavras, "para quem iriam vender este arroz?". Nos dois primeiros anos, a comercialização era, exclusivamente, 
intermediada pela CONAB e se deu dentro de programas do Governo Federal, em parceria com prefeituras locais. A Cooperativa Sul Ecológica e a CAPA (Centro de Apoio ao Agricultor) compravam os produtos da agricultura familiar e distribuíam, juntamente com a Prefeitura de Pelotas, para às pessoas em situação de risco ou em situações de necessidade, como por exemplo para creches, asilos e escolas (REVICA, 2012, GIGOTE, 2012). Essa prática comercial do arroz orgânico funcionou bem nas duas primeiras safras em 2003/04 e 2004/05. Porém, a partir da safra de 2005/06 o NEMA não conseguiu vender para o governo e, por consequência, teve de vender todo o seu arroz orgânico na categoria de convencional. Esse fato foi um grande desestimulo ao grupo (GIGOTE, 2012).

$\mathrm{Na}$ tentativa de solucionar a questão de como vender seu produto, os produtores do NEMA apostaram em uma marca própria, anteriormente já definida no momento da venda do arroz ao governo, chamada "Amigo do TAIM". Essa marca existe até hoje. Contudo, seu primeiro modelo de embalagem era em saquinhos plásticos, o que propiciava a aparição de gorgulhos no grão (REVICA, 2012).

Independente das vendas de arroz aos programas do governo, o mercado exigia certificação dos produtos orgânicos. Como forma de solucionar essas questões dos bichos no arroz e a da necessidade de certificação, surgiu, na safra de 2006/07, a parceria com a Empresa Beneficiadora Josapar, que, desde então, embala o "Amigo do TAIM" a vácuo e, em seguida, o contrato com a Certificadora ECOCERT Brasil. Sendo que essas ligações se mantêm até hoje (GIGOTE, 2012).

Desde a safra 2003/04, quando a comercialização do produto era intermediada pelo Governo Federal, até as safras atuais, com as vendas para Josapar, o preço recebido pelo saco do arroz orgânico "Amigo do TAIM", a não ser na safra de 2005/06, conforme já citado, foi e é de $30 \%$ sobre o preço do saco do arroz convencional. E a Josapar, além de pagar ao produtor, paga também 15\% sobre os preços dos produtos convencionais para o NEMA, que, com esse recurso, arca com as despesas de assistência técnica e de certificação do grupo. Portanto, na verdade, a Josapar paga $45 \%$ a mais pelo arroz orgânico (REVICA, 2012).

O NEMA é certificado como operador de um sistema que envolve certos produtores e certas unidades de secagem. O valor que a Josapar paga ao NEMA é o que possibilita a realização desse sistema (REVICA, 2012). O trabalho intermediário que o NEMA realiza é um incentivo crucial para os agricultores envolvidos, pois, além de reduzir significativamente os custos de uma certificação individual, os produtores não precisam buscar por assistência técnica nem se envolverem com tarefas comerciais (ENRINEQUA, 2012; LAKA, 2012).

Desde a safra 2006/07, toda a comercialização da produção de arroz orgânico do NEMA é vendida para a Josapar. $O$ produtor colhe, faz a secagem, e, então, o NEMA fornece à empresa 0 arroz em casca, que chamam de matéria-prima. A Josapar, que desenvolveu uma linha de produção a vácuo, beneficia esse arroz e comercializa em 3 (três) marcas: "Tio João", "Amigo do TAIM" e "Taeq" (REVICA, 2012).

A quantidade de arroz embalado com a marca "Amigo do TAIM" se estabelece conforme solicitação do NEMA à Josapar. Devido a esse grupo de produtores não apresentar um sistema comercial, a marca é mais considerada institucional do que como comercial. (REVICA, 2012). De qualquer forma, o interesse do produtor é vender a sua safra, o seu arroz em casca. Não importando, necessariamente, com qual marca este será embalado (ENRINEQUA, 2012; GOGOTE, 2012; LAKA, 2012).

Na safra de 2007/2008, o NEMA tinha um total de 7 (sete) produtores do arroz orgânico. No ano seguinte, esse número baixou para 5 (cinco). Mesmo com essa diminuição, foi somente até a safra de 2008/2009 que o grupo conseguiu produzir uma quantidade que a Josapar acabava por ter sobra do produto, tendo estoque que passava de um ano para o outro (REVICA, 2012). Porém, a partir de 2011, o NEMA entregou uma quantidade menor do que a empresa solicitou. Isso 
se dá porque a demanda por produtos orgânicos tem aumentado. E não se pode simplesmente transferir parte do pedido para outros produtores, possivelmente, porque o sistema de orgânico tem uma série de restrições (GIGOTE, 2012).

O NEMA, em 2011, chegou a ter 12 (doze) produtores no sistema de orgânicos, em uma área de 200 hectares plantados. Porém, em 2012, os produtores vinculados à ATLA, que atuavam junto ao NEMA, saíram das atividades agrícolas. O que levou o grupo a um número de 5 (cinco) produtores em 160 hectares (GIGOTE, 2012).

Todos os produtores da ATLA eram pequenos produtores dentro de uma categoria de agricultura familiar, em pequenas áreas, eles desenvolviam tanto a produção orgânica quanto a de arroz convencional, e poucos deles conseguiram diversificar a produção, no sentido de terem outras fontes de renda, como produção de hortaliças, ovinos, entre outros (REVICA, 2012).

A saída desses produtores do campo não se deu em razão de insucesso na produção orgânica, mas sim devido a estess já terem sido prejudicados pelo baixo preço recebido pela safra de convencionais em duas das suas últimas safras, o que os levou à falência em todas as demais produções (REVICA, 2012).

\section{LIMITAÇÕES}

O objetivo da pesquisa é de identificar os grupos de produção orgânica no estado do Rio Grande do Sul e as inovações associadas à produção orgânica desses grupos. O atual estágio da pesquisa possibilitou identificar dois grupos de produtores orgânicos. Sabe-se que há outros grupos. Estes estão sendo contatados para dar continuidade na pesquisa. Quando às inovações, os resultados do grupo dos produtores associados ao NEMA estão em análise. O outro grupo encontra-se em fase de coleta de dados.

\section{RECOMENDAÇÕES DE ESTUDO}

Ainda que tenha sido possível constatar que novas alternativas mais sustentáveis estejam sendo adotadas pelos produtores de arroz, e que esse tipo de cultivo vem crescendo nas últimas safras, para continuidade da pesquisa, se faz necessária a identificação e descrição dos novos empreendimentos produtores de arroz orgânico emergentes, bem como a identificação das inovações dos dois grupos descritos neste artigo. 


\section{REFERÊNCIAS}

ABERNATHY, William; UTTERBACK, James. Patterns of industrial innovation. Techonology Review, v. 80, n.7, p. 40-47, 1978.

ANUÁRIO BRASILEIRO DO ARROZ 2011. Disponível em: <http:// w w w.gaz.com.br/tratadas/eo_ edicao/3/2011/03/20110311_7c80f2d35/ pdf/2803_arroz2011flip.pdf> Acesso em abril de 2012.

ARUNDEL, Anthony et al. The future of innovation measurements in Europe: concepts, problems and pratical directions. Disponível em: < www.step.no/projectarea/ IDEA/papers.html>. Acesso em março 2008.

BARDIN, L. Análise de conteúdo. Lisboa: Edições 70, 1977.

Brasil. Ministério da Agricultura, Pecuária e Abastecimento. Cadeia produtiva de produtos orgânicos / Ministério da Agricultura, Pecuária e Abastecimento, Secretaria de Política Agrícola, Instituto Interamericano de Cooperação para a Agricultura ; coordenadores Antônio Márcio Buainain e Mário Otávio Batalha. - Brasília : IICA : MAPA/SPA, 2007. 108 p. ; 17,5 x $24 \mathrm{~cm}-$ (Agronegócios ; v. 5)

BRASIL. Ministério da Agricultura. Legislação Brasileira. Disponivel em: <http://www. prefiraorganicos.com.br/media/5806/ lei_n-10831_de_23-12-2003.pdf>. Acesso em: Abril/2011.

BRASIL. Ministério da Fazenda. Economia Brasileira em Perspectiva. Disponível em: < http://www.fazenda.gov.br/portugues/docs/ perspectiva-economia-brasileira/link.htm> Acesso em abril de 2012.

BRASIL. Lei no 10.831, de 23 dezembro de 2003. Dispõe sobre a agricultura orgânica e dá outras providências. Disponível em: http:// www. planetaorganico.com.br/lei23dez03. htm. Acesso em: 20 de janeiro de 2006.
CARACA, J.; LUNDVALL, B. A.; MENDONÇA, $S$. The changingmrole of science in the innovation process: from queen to Cinderella? Technological Forecasting and Social Change, San Diego. V. 76, n. 6, p. 861-867, 2009.

COCEARGS - Cooperativa Central dos Assentamentos do Rio Grande do Sul Ltda. Entrevista realizada com técnico agropecuário Fabio, em 12 de junho de 2012.

COHEN, Wesley M. \& LEVINTHAL, Daniel A. Capacity absortive: a new perspective on learning and innovation. Administrative Sciense Quaterly, v.35, p.128-152, 1990.

ENRINEQUA, Santa Vitória do Palmar - RS: maio 2012. Produtor de Arroz Convencional e do Arroz Orgânico, vinculado ao NEMA. Descrição da evolução do sistema de produção orgânico dos produtores associados ao NEMA. Foi entrevistado por Graziela Mota Antunes na Prefeitura Municipal de Santa Vitória do Palmar

FAO. Agricultura Munial: hacia los anõs 2015/2030- Informe resumido, 2002. 97p.

FAO. Food and agriculture organization fao. World agriculture: towards 2015/2030: prospects by major sector: crop production. Summary report, 2008. Disponível em:<http:// www.fao.org/docrep/004/y3557e.08.ttm. Acesso em: 07 de jun. 2011.

FREEMANN, C. Introdução In: DOSI, Giovani et al. Technical change and economic theory. London: Printer Publishers, 1988. p. 1-12.

GIGOTE, Santa Vitória do Palmar - RS: maio 2012. Engenheiro Agrônomo que assessoria a produção de Arroz Orgânico, vinculada ao NEMA. Descrição da evolução do sistema de produção orgânico dos produtores associados ao NEMA. Foi entrevistado por Graziela Mota Antunes na Prefeitura Municipal de Santa Vitória do Palmar.

GLOBO. Orgânicos possuem mais nutrientes do que alimentos convencionais. Disponível em: <http://video.globo.com/Videos/Player/ 
Noticias/0,,GIM1469642-7823-ORGANICOS+P OSSUEM+MAIS+NUTRIENTES+DO+QUE+ALIM ENTOS+CONVENCIONAIS,00.html>. Acesso em março/2011.

GRUPO GESTOR ARROZ ECOLÓGICO. COCEARGS. Folheto da 9a Abertura da Colheita do Arroz Ecológico. Safra 2011/2012. Assentamento Nova Capela. Nova Santa Rita/ RS. 02 de abril de 2012.

HART, S. L.; MILSTEIN, M. B.. Creating sustainable value. Academy of Management Executive. New York, v. 17, n. 2, p-56-57, 2003

IRGA. Instituto Rio Grandense de Arroz. Disponível em: <www.irga.> Acesso em maio de 2012.

JORDE, Thomas M. \& TEECE, David J. Competition and Cooperation: striking the right balance. California Management Review - Business \& Public Policy, Califórnia, spring 1989.

KEMP, René; ARUNDEL Anthony. Survey Indicators for Environmental Innovation. Oslo, IDEA report, STEP Group, 1998.

KEMP, René; PEARSON, Peter. Final report of the project Measuring Eco- Innovation. Maastricht, MEI (Measuring Eco-Innovation), 2007.

KNIGHT, Kenneth E. A descriptive model of intra-firm innovation process. Journal of Business. v.40, p. 478-496, 1967.

LAKA, Santa Vitória do Palmar - RS: maio 2012. Produtor de Arroz Orgânico, vinculado ao NEMA. Descrição da evolução do sistema de produção orgânico dos produtores associados ao NEMA. Foi entrevistado por Graziela Mota Antunes na Prefeitura Municipal de Santa Vitória do Palmar.

LOVINS, A. B.; LOVINS, L. H.; HAWKEN, P. A road map for natural capitalism. :Harvad Business Review. Boston, v. 85, n. 7-8, p. 172-183, 2007.
MENEGON, Leandro L.; FAGUNDES, Leandro. RIBEIRO, Orestes. CADORE, Edson. Produção de Arroz Agroecológico em Assentamentos de Reforma Agrária no entorno de Porto Alegre. Rev. Bras. De Agroecologia, v. 4 n. 2, nov. 2009 MIOTTI, Luis; SACHWALD, Frédérique. Cooperative P\&D; Why and with whom? An integrated framework of analysis. Research Policy. v. 16, n.7, p.1-19, 2003.

NALEBUFF, Barry; BRANDENBURGER, A. Coopetição. São Paulo: Rocco, 1996.

NASSAR, A. M.. Certificação no agrobusiness. In: SEMINÁRIO Internacional PENSA de Agrobusiness: A Gestão da Qualidade dos Alimentos, 9a Cap. 3, p. 16-30, 1998.

NEMA. Núcleo de Educação e Monitoramento Ambiental em Rio Grande. Site. Disponível em: < http://www.nema-rs.org.br/> Acesso em abril de 2012.

OECD/FAO. Agricultural Outlook 2008-29017: highlights, 2008. Disponível em: HTTP:// www.fao.org/es/esc/common/ecg/550/en/ AgOut2017E.pdf. Acesso em: 7 de jun. 2011.

PIGATTO, Giuliana Aparecida Santini; SCHIAVI, Sandra Mara de Alencar, SOUZA FILHO, Hildo Meirelles de Souza. Techonological innovation in agri-food chains: the cases of meat, milk and coffee chains in Brazil. V International PENSA Conference on Agri-food Chains/Networks Economics and Management. July 27-29, Ribeirão Preto, 2005.

PROBIO. Relatório de atividades 2002-2004 / Ministério do Meio Ambiente. Projeto de Conservação e Utilização Sustentável da Diversidade Biológica Brasileira; texto de Daniela América Suárez de Oliveira e Cilúlia Maury. - Brasília: Ministério do Meio Ambiente, 2004.

REVICA. Rio Grande - RS: abr. 2012. Coordenador dos Projetos Comunidades do Taim: educação ambiental e sustentabilidade. Descrição da evolução do sistema de produção 
orgânico dos produtores associados ao NEMA

. Foi entrevistado por Graziela Mota Antunes na sede do NEMA.

SOSBAI - Sociedade Sul-Brasileira de Arroz Irrigado. ARROZ IRRIGADO, 2010.

SOUZA FILHO, H. M. S. Desenvolvimento agrícola sustentável. In: BATALHA, M. O. (Ed.). Gestão agroindustrial. São Paulo: Atlas, 2001. p. 585-626

SOUZA, M. C. M.. Produtos orgânicos. In: NEVES; ZYLBERSZTAJN. Economia e gestão dos negócios agroalimentares. São Paulo: Pioneira, 2000. p. 385-401

THETER, B. Who co-operantes for innovation and why: an empirical analysis. Research Policy. Amsterdam, v. 31, n. 6, p. 947-967, apr. 2002.

TIDD, J.; BEASSANT, J.; PAVITT, K. Managing innovation: integrating technological, market and organizational change. Chinchester: Wiley, 1997.

TILMAN, D. et al. Forecasting agriculturally driven global environmental change. Science. New York. V. 292, n. 5515, p. 281-284. 2001.

VIGNOLO, ANTONIO M. S. Insumos Orgânicos na Produção de Arroz em Assentamentos da Reforma Agrária - Região de Porto Alegre/RS. Dissertação. Programa de Pós-Graduação em Agroecossistemas, Centro de Ciências Agrárias Universidade Federal de Santa Catarina. Florianópolis, 2010. 